\title{
Acute lower motor neuron syndrome and spinal cord gray matter hyperintensities in HIV infection
}

\section{OPEN}

Isaac I. Bogoch, MD* Michael R. Wilson, MD* David A. Chad, MD Nagagopal Venna, MD

Correspondence to Dr. Bogoch: isaac.bogoch@uhn.ca

\section{ABSTRACT}

Objective: To describe a novel manifestation of lower motor neuron disease in patients with wellcontrolled HIV infection.

Methods: A retrospective study was performed to identify HIV-positive individuals with acute, painful lower motor neuron diseases.

Results: Six patients were identified with HIV and lower motor neuron disease. Two patients met the inclusion criteria of well-controlled, chronic HIV infection and an acute, painful, unilateral lower motor neuron paralytic syndrome affecting the distal portion of the upper limb. These patients had segmental T2-hyperintense lesions in the central gray matter of the cervical spinal cord on MRI. One patient stabilized and the second patient improved with immunomodulatory therapy.

Conclusions: This newly described syndrome expands the clinical spectrum of lower motor neuron diseases in HIV. Neurol Neuroimmunol Neuroinflamm 2015;2:e113; doi: 10.1212/ NXI.0000000000000113

\section{GLOSSARY}

ALS = amyotrophic lateral sclerosis; $\mathbf{A R T}=$ antiretroviral therapy; $\mathbf{B A D}=$ brachial amyotrophic diplegia; $\mathbf{I g}=$ immunoglobulin; LMN = lower motor neuron.

Lower motor neuron (LMN) diseases related to HIV are rare and frequently mimic amyotrophic lateral sclerosis (ALS). ${ }^{1}$ This syndrome of muscle atrophy and weakness is typically subacute and responds to antiretroviral therapy (ART). Here we describe 2 cases of an HIV-related motor neuron syndrome characterized by an acute, painful, unilateral segmental cervical motor neuronopathy affecting predominantly the distal portion of the upper limb in virologically suppressed individuals. In both cases, MRI of the cervical spinal cord disclosed segmental T2-hyperintense lesions in the central gray matter.

METHODS A retrospective study was performed with permission from the Partners Research Ethics Board. We searched our online medical database for cases of LMN disease in the context of HIV infection at the Massachusetts General Hospital between July 1996 and July 2011. Inclusion criteria included HIV infection, LMN disease, acute onset of symptoms, and a painful, unilateral syndrome. Identified charts were reviewed in detail and responses to therapy were documented.

RESULTS Six patients with HIV infection and LMN disease were identified. Four patients were excluded because they did not meet inclusion criteria-all demonstrated a bilateral process at presentation and had no pain. The 2 patients that met inclusion criteria are described in detail below.

Patient 1. A 62-year-old man presented in March 2009 with new, rapidly worsening left hand weakness heralded by left scapular pain that radiated down the upper arm and forearm and into his hand. Two days after the onset of pain, severe weakness developed in the fingers, wrist, and forearm, resulting in a flaccid

*These authors contributed equally to the manuscript.

From the Divisions of Internal Medicine and Infectious Diseases (I.I.B.), University Health Network, Toronto, Ontario, Canada; Department of Medicine (I.I.B.), University of Toronto, Ontario, Canada; Department of Neurology (M.R.W.), University of California, San Francisco; Department of Neurology (D.A.C., N.V.), Massachusetts General Hospital, Boston, MA; and Harvard Medical School (D.A.C., N.V.), Boston, MA.

Funding information and disclosures are provided at the end of the article. Go to Neurology.org/nn for full disclosure forms. The Article Processing Charge was paid by the authors.

This is an open access article distributed under the terms of the Creative Commons Attribution-Noncommercial No Derivative 4.0 License, which permits downloading and sharing the work provided it is properly cited. The work cannot be changed in any way or used commercially. 
paralysis of his hand. The pain resolved in a few days, but his weakness persisted. There were no other motor, sensory, or constitutional symptoms, and there was no history of trauma or medication changes.

The patient was diagnosed with HIV in 2006, at which time his viral load was greater than 500,000 copies $/ \mathrm{mL}$ and his CD 4 count was 4 cells $/ \mathrm{mL}$. At the time of his HIV diagnosis, examination of the left upper extremity demonstrated dystonia of the hand, atrophy and fasciculations in the deltoid and biceps, and an absent biceps reflex consistent with an LMN syndrome of the C5 and C6 myotomes. Cervical spine MRI revealed multilevel discogenic degenerative arthropathy with lateral and central canal stenoses. In addition, there were unusual symmetrical nonenhancing areas of T2-hyperintense signal localized to the central gray matter of the cord at C3-C4 and C6-C7 (figure, A and B). Because the spondylotic changes did not fully explain the clinical syndrome and the central cord myelopathic changes, neurosurgery deferred cervical decompression. No evidence for opportunistic infections was found. Indeed, the left hand dystonia resolved dramatically and the atrophy and fasciculations in the arm diminished markedly within months of initiating ART consisting of tenofovir, emtricitabine, and efavirenz.

The neurologic examination performed at the time of his 2009 presentation for left upper extremity pain and weakness was significant for a power grade of $0 / 5$ for left finger abduction and adduction, finger extension and flexion, and thumb abduction and opposition. Left elbow extension was graded at 2/5

\section{Figure Spinal cord imaging}

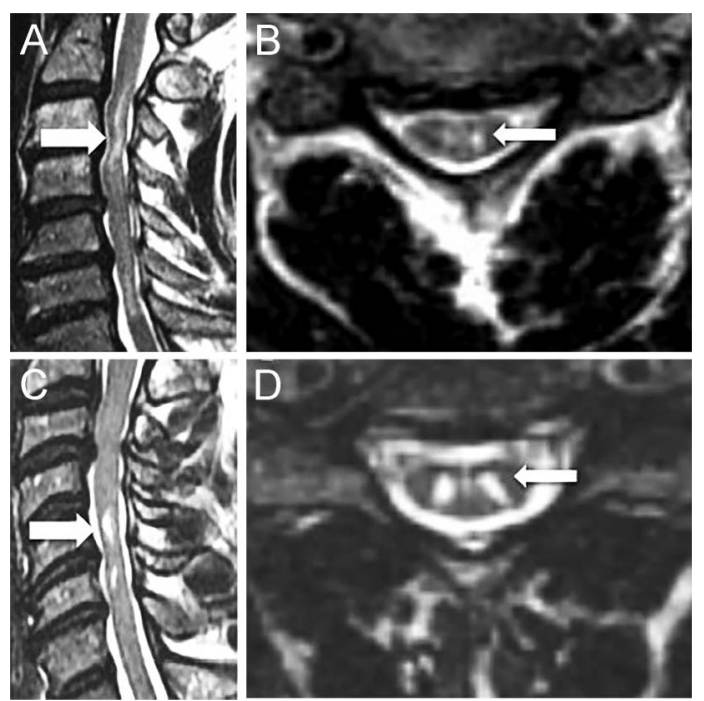

(A, B) Sagittal and axial T2-weighted cervical spine MRI demonstrating hyperintensities in the central gray matter of patient 1 (arrows). (C, D) Sagittal and axial T2-weighted cervical spine MRI demonstrating hyperintensities in the central gray matter of patient 2 (arrows). with fully preserved elbow flexion strength. Upper extremity reflexes were absent bilaterally. Fasciculations were seen in the left biceps and deltoid muscles, as before. There were no sensory deficits in the left upper limb. The rest of the neurologic examination, including gait and balance, was normal. Cervical spine MRI was unchanged from 2006, with no significant worsening of the degenerative disc disease and persistent gray matter abnormalities at $\mathrm{C} 3-\mathrm{C} 4$ and C6-C7 (figure, A and B). Brain MRI was normal. Nerve conduction and EMG studies performed 24 days after onset of weakness demonstrated a severely reduced left median motor response with prolonged distal motor latency, slowed median motor conduction velocity, and prolonged F-wave latency, all of which were considered commensurate with the loss of fast-conducting motor fibers or their motor neurons. The left ulnar response was also severely reduced. (The right median and ulnar motor conduction studies, including F-wave latencies, were normal.) There was no evidence for significant sensory dysfunction or partial motor conduction block. Coupled with the needle electrode examination showing severe acute denervation in the left C8 and T1 myotomes, the findings were consistent with segmental anterior horn cell injury at the level of the cervical spinal cord. Serum HIV load was undetectable, and CD4 cell count was 150 cells $/ \mathrm{mL}$. Both levels had been stable for more than 2 years. CSF was not tested. The clinical and EMG findings correlated with the gray matter lesions at the level of the $\mathrm{C} 7$ vertebral body, as this corresponds to the C8 and T1 segments of the cord. Given a possible parainfectious or autoimmune mechanism, he was empirically treated with prednisone $60 \mathrm{mg} / \mathrm{day}$ for 1 week, along with occupational and physical therapy. Left hand strength after 6 weeks had improved to 2/5 in finger flexion, extension, abduction, and adduction but eventually regressed to total paralysis.

In July 2010, the patient presented with new right hand pain and weakness progressing over 4 days accompanied by sharp pain in the right shoulder and arm. Neurologic examination showed weakness of the right hand with power grade $3 / 5$ for finger flexion, 2/5 for finger abduction and adduction, and 2/5 for thumb abduction and opposition. The left hand remained paralyzed. Reflexes were $1+$ in the upper extremities. Strength was preserved at the deltoids, biceps, and triceps bilaterally, with occasional fasciculations in the deltoid and biceps muscles, as before. The rest of his neurologic examination was normal.

Cervical spine MRI was unchanged except for some mild cord atrophy at C4-C5 and C6-C7 where the T2-hyperintense gray matter abnormalities persisted. Nerve conduction studies of the right median, ulnar, and radial nerves, and the medial and lateral 
antebrachial cutaneous nerves disclosed normal responses, whereas the right median, ulnar, and radial motor responses were moderately to markedly reduced. The needle examination disclosed active and chronic denervation changes in a multisegmental (C5-C6, C7, and C8) distribution, a pattern of findings that localized to the motor portion of the peripheral nervous system proximal to the dorsal root ganglia-a cervical polyradiculopathy or segmental myelopathy. Serum HIV load remained undetectable, and the CD 4 count was 161 cells/mL. CSF revealed 3 white blood cells, glucose $75 \mathrm{mg} / \mathrm{dL}$, and protein 86 $\mathrm{mg} / \mathrm{dL}$ (normal range $55 \mathrm{mg} / \mathrm{dL}$ ) without organisms on stains and culture. CSF PCR for JC virus, HIV, enteroviruses, varicella-zoster virus, herpes simplex virus, and Epstein-Barr virus was negative. There was no serologic evidence of hepatitis $B$, hepatitis C, or syphilis. Serum vitamin $B_{12}$ was normal. Rheumatoid factor, antinuclear, and double-stranded DNA antibodies were negative. Serum immunoglobulin (Ig) levels were normal. Stool sample for poliovirus by PCR was negative.

Reasoning that the pathophysiology was parainfectious or autoimmune (similar to the 2009 episode), the patient was treated for 5 days with IVIg. The deterioration of hand strength abated, and 6 weeks later right finger abduction and adduction, thumb abduction and opposition, and finger flexion and extension improved to $3 / 5$ strength. His examination remained unchanged 12 months later.

Patient 2. A 53-year-old man was evaluated in October 2010 for 2 months of progressive numbness and pain in the left 4th and 5th fingers extending to the elbow. The pain was severe and woke him from sleep but gradually subsided as his hand weakness became obvious. There were no other neurologic or systemic symptoms.

His HIV infection, diagnosed in 1997, had been well-controlled on an ART regimen consisting of darunavir, ritonavir, and tenofovir/emtricitabine for 4 years. CD4 counts were greater than 500 cells $/ \mathrm{mL}$, and viral loads had been undetectable for more than 1 year. He had failed interferon therapy for his hepatitis $\mathrm{C}$ infection in 2003. He had not used IV drugs for 6 years.

The only prior neurologic history was in 2000 when he was evaluated for daily episodes of paresthesia extending from the left shoulder to the hand lasting from seconds to minutes and often accompanied by weakness in the arm. Cervical spine MRI showed multilevel degenerative arthropathy and disc disease without central canal stenosis. An unexpected focus of intramedullary central gray matter T2 hyperintensity was also found at the C5 vertebral body level (more prominent ventrally) and was not associated with cord expansion (figure, C and D). His symptoms resolved spontaneously over a few months.

In 2010, the neurologic abnormalities were limited to the left upper extremity, with $4 / 5$ weakness in finger abduction and adduction, finger extension, and thumb abduction and opposition. There was no focal muscular wasting or fasciculations. Upper extremity reflexes were $2+$ and symmetric. There was a slight decrease of sensation to light touch, pinprick, and vibration sense in the palmar aspect of the left 4th and 5th fingers. There were no long tract signs in the lower limbs other than a right upgoing toe. Gait and balance were normal. Cervical spine mobility was normal.

At the time of examination, serum HIV was undetectable and the CD4 count was 600 cells $/ \mathrm{mL}$. Serum vitamin $B_{12}$, C-reactive protein, erythrocyte sedimentation rate, and angiotensin-converting enzyme were within normal limits. Serum tests for rheumatoid factor, cryoglobulins, antinuclear, and extractable nuclear antigens were negative; anti-treponemal antibodies were negative. Serum Ig electrophoresis was normal. CSF demonstrated no white blood cells, glucose $64 \mathrm{mg} / \mathrm{dL}$, and protein $31 \mathrm{mg} / \mathrm{dL}$, with no organisms visualized or cultured. CSF Venereal Disease Research Laboratory was negative. CSF PCRs for Epstein-Barr virus, herpes simplex virus, varicellazoster virus, JC virus, cytomegalovirus, HIV, and West Nile virus were negative. PCR for poliovirus was negative in a stool sample.

MRI showed enlargement of the bilateral nonenhancing gray matter $\mathrm{T} 2$ hyperintensity at $\mathrm{C} 5$ and a new lesion extending from C6-T1 (figure, C and D). Nerve conduction studies were performed 2 months after the onset of symptoms. Sensory studies of the left median, ulnar, and radial nerves, and the lateral and medial antebrachial cutaneous nerves disclosed normal responses; the left median and ulnar motor responses were also normal. The needle examination disclosed active denervation and reduced motor unit potential recruitment in left upper limb muscles (ulnar-supplied first dorsal interosseus and radial-supplied extensor indicis proprius and extensor digitorum communis) deriving innervations from the C7 and C8 cervical segments (left cervical paraspinal muscles also showed active denervation changes). These changes were consistent with the presence of a cervical polyradiculopathy or segmental cervical myelopathy.

The subacute LMN syndrome was again felt to be parainfectious or autoimmune and related to HIV because no alternative etiology could be identified. He was treated with IVIg $400 \mathrm{mg} / \mathrm{kg} /$ day for 4 days, monthly for 12 months. The severe pain in the left upper limb and the sensory changes disappeared within 2 weeks. By 6 months, hand strength was full, 
and there was no recurrence of symptoms in the following 2 years. The T2-hyperintense signals in the cervical cord MRI at the C5 and C6 levels had not changed on repeat imaging 6 months later.

DISCUSSION HIV-related motor neuron disorders were first described in 1985 and remain a rare manifestation of HIV infection. Motor neuron syndromes in HIV-positive individuals can mimic ALS, and ALS-like syndromes are more common in HIVpositive patients than the general population. ${ }^{2-4}$ An immune-mediated mechanism is suspected, as neurons are not known to be infected by HIV., ${ }^{5,6} \mathrm{~A}$ rare LMN disorder known as brachial amyotrophic diplegia (BAD) has also been described in HIVpositive patients, including those with undetectable viral loads. ${ }^{7-9}$ It is characterized by gradually progressive proximal upper extremity weakness and wasting and is also referred to as "flail arm syndrome."10,11 LMN disease is more common when HIV infection is poorly controlled and symptoms stabilize or reverse after ART initiation, as occurred in our first patient before his subsequent decline 2 years later. ${ }^{2}$

Although $2 \mathrm{HIV}$-positive patients with BAD have been reported to have gray matter spinal cord abnormalities on MRI, the patients described in this report had rapidly evolving neurologic syndromes characterized by distal upper limb weakness heralded by pain. ${ }^{7,9}$ The clinical, electrophysiologic, and neuroimaging characteristics of the patients we report may be conceptualized as an acute segmental cervical poliomyelopathy. The upper limb pain and weakness experienced by our patients led us to consider the possibility that they might have had a manifestation of brachial plexus neuropathy or neuralgic amyotrophy (i.e., Parsonage-Turner syndrome), as has been described in HIV-infected patients. ${ }^{12,13}$ In both patients, however, there was conspicuous sparing of sensory responses that are normally subserved by pathways derived from all portions of the brachial plexus. These spared sensory responses in the setting of marked motor axon loss (as manifested by attenuation of motor responses and active and chronic denervation in a multisegmental distribution in patient 1 and the involvement of the C7 and C8 segments with paraspinal involvement in patient 2) would be unusual in a brachial plexus lesion. Indeed, in lesions of the brachial plexus, attenuation or loss of sensory responses is very common ${ }^{14}$ and is considered to provide "one of the most useful pieces of information to help differentiate plexus from root lesions." 15 In contrast, the sparing of sensory responses in the patients reported here strongly suggests a preganglionic site of pathology to explain the clinical features and correlates with the presence of spinal cord signal changes on MRI. The clinical picture described in our report is reminiscent of poliomyelitis; however, there were no inflammatory changes in the CSF and the CSF enterovirus PCRs and stool PCR for poliovirus were negative. Lastly, it is important to contrast this syndrome with HIV vacuolar myelopathy, a late manifestation of AIDS that presents as progressive spastic paraparesis and ataxia coupled with bowel and bladder dysfunction over a period of months.

It is important to note that both patients' MRI abnormalities were chronic and were associated initially with mild clinical abnormalities. The 2 episodes of acute weakness in the first patient and the single event of subacute weakness in the second patient were superimposed on a preexisting gray matter myelopathy. Another notable factor is that the limb weakness in each episode was unilateral while the MRI changes were bilateral. This, along with chronic low-grade LMN signs of fasciculations in the proximal segments of the upper arms in the first patient, points to an acute-on-chronic motor neuron injury. The late segmental cord atrophy in the first patient is indicative of tissue loss as a result of this process. A confounding issue is the substantial multilevel cervical spondylosis resulting in foraminal and central canal stenoses. This process may have predisposed the patients to a segmental LMN disorder.

The underlying pathogenesis of this described LMN disorder in our patients is unknown. It is notable that the neurologic condition appeared while the patients were on stable ART regimens with undetectable serum HIV by PCR and stable CD4 counts. No evidence of opportunistic infections was found, especially for neurotropic viruses. HIV escape into the CNS was excluded by finding an undetectable HIV load in the CSF. We suspected an indirect (e.g., parainfectious) effect of HIV infection on the cervical cord motor neurons and possibly the motor nerve roots by a putative autoimmune mechanism. This was the basis for empiric treatment with prednisone and IVIg. This treatment strategy was associated with clinical stabilization in the first patient and recovery in the second patient. In summary, we describe 2 virally suppressed patients whose clinical, electrophysiologic, neuroimaging, and treatment response expand the spectrum of motor neuron diseases associated with HIV.

\section{AUTHOR CONTRIBUTIONS}

I.I.B.: drafting/revising the manuscript, study concept, analysis, acquisition of the data. M.R.W.: drafting/revising the manuscript, study concept, analysis, acquisition of the data. D.A.C.: drafting/revising the manuscript, analysis of the data. N.V.: drafting/revising the manuscript, study concept, analysis of the data, study supervision.

\section{STUDY FUNDING}

Supported by the American Brain Foundation Clinical Research Training Fellowship (to M.R.W.) 


\section{DISCLOSURE}

I.I. Bogoch reports no disclosures. M.R. Wilson received research support from NIH/National Center Advancing Translational Science, Clinical and Translational Science Institute and American Brain Foundation. D.A. Chad and N. Venna report no disclosures. Go to Neurology.org/nn for full disclosure forms.

Received October 8, 2014. Accepted in final form April 2, 2015.

\section{REFERENCES}

1. Hoffman PM, Festoff BW, Giron LT Jr, Hollenbeck LC, Garruto RM, Ruscetti FW. Isolation of LAV/HTLV-III from a patient with amyotrophic lateral sclerosis. N Engl J Med 1985;313:324-325.

2. Moulignier A, Moulonguet A, Pialoux G, Rozenbaum W. Reversible ALS-like disorder in HIV infection. Neurology 2001;57:995-1001.

3. Sinha S, Mathews T, Arunodaya GR, et al. HIV-1 cladeC-associated "ALS”-like disorder: first report from India. J Neurol Sci 2004;224:97-100.

4. Verma A, Berger JR. ALS syndrome in patients with HIV1 infection. J Neurol Sci 2006;240:59-64.

5. Gonzalez-Scarano F, Martin-Garcia J. The neuropathogenesis of AIDS. Nat Rev Immunol 2005;5:69-81.

6. Robert ME, Geraghty JJ III, Miles SA, Cornford ME, Vinters HV. Severe neuropathy in a patient with acquired immune deficiency syndrome (AIDS). Evidence for widespread cytomegalovirus infection of peripheral nerve and human immunodeficiency virus-like immunoreactivity of anterior horn cells. Acta Neuropathol 1989;79:255-261.

7. Berger JR, Espinosa PS, Kissel J. Brachial amyotrophic diplegia in a patient with human immunodeficiency virus infection: widening the spectrum of motor neuron diseases occurring with the human immunodeficiency virus. Arch Neurol 2005;62:817-823.

8. Cachia D, Izzy S, Ionete C, Salameh J. Brachial amyotrophic diplegia in the setting of complete HIV viral load suppression. BMJ Case Rep 2012. doi: 10.1136/bcr2012-007632; pii: bcr2012007632.

9. Henning F, Hewlett RH. Brachial amyotrophic diplegia (segmental proximal spinal muscular atrophy) associated with HIV infection. J Neurol Neurosurg Psychiatry 2008;79:1392-1394.

10. Czaplinski A, Steck AJ, Andersen PM, Weber M. Flail arm syndrome: a clinical variant of amyotrophic lateral sclerosis. Eur J Neurol 2004;11:567-568.

11. Nalini A, Desai A, Mahato SK. Flail arm-like syndrome associated with HIV-1 infection. Ann Indian Acad Neurol 2009;12:127-130.

12. Bellagamba R, Tommasi C, De Marco M, Narciso P. Parsonage-Turner syndrome: a rare case of abacavir hypersensitivity reaction in HIV-infected patients. J Infect 2008; 57:88-90.

13. McNamara P, Kiely BM, Zekan S, Redmond J, Mulcahy F. Bilateral brachial neuritis secondary to varicella reactivation in an HIV-positive man. Int J STD AIDS 2012;23:145-146.

14. Ferrante MA, Wilbourn AJ. Electrodiagnostic approach to the patient with suspected brachial plexopathy. Neurol Clin 2002;20:423-450.

15. Preston DC, Shapiro BE. Electromyography and Neuromuscular Disorders: Clinical-Electrophysiologic Correlations, 3rd ed. London, UK: Elsevier; 2013. 


\title{
Neurology \\ Neuroimmunology \& Neuroinflammation
}

\author{
Acute lower motor neuron syndrome and spinal cord gray matter hyperintensities in \\ HIV infection \\ Isaac I. Bogoch, Michael R. Wilson, David A. Chad, et al. \\ Neurol Neuroimmunol Neuroinflamm 2015;2; \\ DOI 10.1212/NXI.0000000000000113
}

This information is current as of May 14, 2015

Updated Information \&

Services

References

Subspecialty Collections

Permissions \& Licensing

Reprints including high resolution figures, can be found at:

http://nn.neurology.org/content/2/4/e113.full.html

This article cites 13 articles, 1 of which you can access for free at: http://nn.neurology.org/content/2/4/e113.full.html\#\#ref-list-1

This article, along with others on similar topics, appears in the following collection(s):

All Infections

http://nn.neurology.org//cgi/collection/all_infections

Anterior nerve cell disease

http://nn.neurology.org//cgi/collection/anterior_nerve_cell_disease HIV

http://nn.neurology.org//cgi/collection/hiv

Spinal cord infection

http://nn.neurology.org//cgi/collection/spinal_cord_infection

Information about reproducing this article in parts (figures,tables) or in its entirety can be found online at:

http://nn.neurology.org/misc/about.xhtml\#permissions

Information about ordering reprints can be found online: http://nn.neurology.org/misc/addir.xhtml\#reprintsus

Neurol Neuroimmunol Neuroinflamm is an official journal of the American Academy of Neurology.

Published since April 2014, it is an open-access, online-only, continuous publication journal. Copyright $($ ) 2015 American Academy of Neurology. All rights reserved. Online ISSN: 2332-7812.

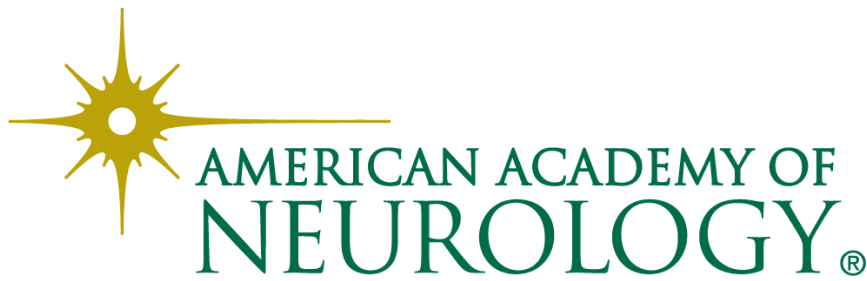

